\title{
Painful lateral foot swelling
}

\author{
Wesley Klejch $^{1}$ - Howard O'Rourke ${ }^{1}$ - George El-Khoury ${ }^{1}$
}

Published online: 19 March 2016

(C) ISS 2016

\begin{abstract}
Answer
\section{Diagnosis}

Calcific tendonitis of peroneus longus.
\end{abstract}

\section{Discussion}

Calcific tendonitis is most prevalent in the tendons of the shoulder and the hip; it has also been described at many other sites including the elbow, wrist, neck, knee, foot and ankle [1, 2]. The peak incidence of calcific tendonitis is in the fourth through sixth decade of life, and the disease has a female predominance [3]. The deposition of hydroxyapatite crystals into muscles, capsules, bursae, and tendon sheaths can be associated with underlying renal disease or collagen vascular disease but often occurs idiopathically.

Radiographs are sufficient to demonstrate the amorphous calcifications seen with hydroxyapatite crystal deposition. However, symptoms may not correlate with the radiographic findings and incidental asymptomatic calcifications have been reported [3]. Cross-sectional imaging can help localize the calcifications to a tendinous or bursal distribution.

The case presentation can be found at doi: 10.1007/s00256-016-2361-3

Howard O'Rourke

Howard-orourke@uiowa.edu

1 Department of Radiology, University of Iowa Hospitals \& Clinics, 200 Hawkins Drive, Iowa City, IA 52242-1077, USA
Early recognition and supportive therapy including NSAIDs, elevation, non-weight bearing, ice, and rest are appropriate first line treatments. If symptoms do not improve with supportive therapy, ultrasound-guided needle lavage, corticosteroid injection and surgical debridement may offer clinical improvement [4-6]; however, with appropriate diagnosis, management, and time, the majority of cases will resolve without surgical intervention.

In our patient, the radiograph demonstrated soft tissue calcifications at the lateral aspect of the cuboid as well as a focus of ossification more distally suggestive of os peroneum (Fig. 1). Initial differential considerations were peroneal longus calcific tendonitis, painful os peroneum syndrome, or possibly tearing of peroneus longus with post-traumatic calcifications. An MRI was obtained the following day, which revealed peroneus longus tendon enlargement with heterogeneous intrasubstance signal along with peritendinous edema and intrasubstance and peritendinous foci of low signal consistent with calcifications (Fig. 2a,b,c). No os peroneum or discrete peroneal tendon tear was identified. AP radiograph of both feet obtained at a later date did not suggest a rightsided os peroneum either, though a dedicated right foot study with oblique view was not obtained.

These findings were interpreted as peroneus longus calcific tendonitis. The patient was treated conservatively with boot and crutches, non-steroidal medication, physical therapy, as well as referral to orthopedics. No lab work was obtained. Repeat radiographs were obtained 2-3 weeks after the initial film, which demonstrated interval decrease in the calcifications (Fig. 3). Patients are often most symptomatic during the resorptive phase of calcific tendonitis.

The incidence of peroneus longus calcific tendonitis is uncommon with few cases reported in the literature [3-5, 7-9]. Patients typically present with acute onset unilateral foot pain with swelling. Full range of motion 
in the ankle, sub-talar, and midfoot joints are preserved $[4,5,7]$. Mild tenderness to palpation in the lateral aspect of the foot proximal to the base of the fifth metatarsal has been described [5, 7]. Patients have no history of trauma to the area but often have a history of working on their feet such as standing on a ladder for extended periods of time, ballroom dancing, and wearing high-heeled shoes [4, 7]. Laboratory examination can reveal mildly elevated ESR, CRP, and leukocytosis $[5,7]$. Radiographic examination demonstrates calcifications within the peroneus longus tendon unilaterally. Peroneus longus calcific tendonitis should be considered in patients with acute onset lateral foot pain without history of trauma, vascular injury, or infection and no radiographic evidence of fracture. The differential diagnosis is broad and includes soft tissue infection, avulsion fracture, and sesamoid bones [7]. At the 3-wk follow up, the swelling and pain in our patient had improved with being placed in a boot and no further intervention was required.

\section{References}

1. Kraemer EJ, El-Khoury GY. Atypical calcific tendinitis with cortical erosions. Skelet Radiol. 2000;29(12):690-6.

2. Holt PD, Keats TE. Calcific tendinitis: a review of the usual and unusual. Skelet Radiol. 1993;22:1-9.

3. Uhthoff HK. Calcifying tendinitis: a new concept of its pathogenesis. Clin Orthop Relat Res. 1976;118:164-8.

4. Cox D, Paterson FW. Acute calcific tendinitis of peroneus longus. J Bone Joint Surg (Br). 1991;73(2):342.

5. Brinsden MD, Wilson JH. Acute calcific tendinitis of the peroneus longus tendon. Injury Extra. 2005;36(10):426-7.

6. Luis del Cura J, Torre I, Zabala R, Legorburu A. Sonographically guided percutaneous needle lavage in calcific tendinitis of the shoulder: short and long term results. AJR Am J Roentgenol. 2007;189: W128-34.

7. Mouzopoulos G, Lasanianos N, Nikolaras G, Tzurbakis M. Peroneus longus acute calcific tendinitis: a case report. Cases J. 2009;2:7453.

8. Klammer G, Iselin LD, Bonel HM, Weber M. Calcific tendinitis of the peroneus longus: case report. Foot Ankle Int. 2011;32(6):638-40.

9. Miller CF. Occupational calcareous peritendinitis of the feet: a case report. Am J Roentgenol Radium Ther. 1949;61(4):506-10. 